\title{
Agrobiological assessment of cotton breeding material in light chestnut soils
}

\author{
Aleksey Ovchinnikov ${ }^{1, *}$, Oybek Kimsanbaev ${ }^{1}$, Valery Antonov ${ }^{1}$, Igor Podkovyrov ${ }^{1}$, \\ Taisia Konotopskaya ${ }^{1}$, and Dmitry Ermak $^{2}$ \\ ${ }^{1}$ Volgograd State Agrarian University, Volgograd, 400002, Russia \\ ${ }^{2}$ All Russian Research Institute of Phytopathology, Moscow Region 143050, Russia
}

\begin{abstract}
The promotion of cotton in regions with long daylight hours is a priority for genetics. The creation of a new breeding material for a crop with a short growing season of 95-110 days makes it possible to organize the production of this fiber in the south of Russia. The studies were carried out in 2014-2020 at the experimental sites of the Volgograd State Agrarian University. Growth, development, ecological and biological characteristics were studied on new cotton varieties PGSSH 1 and PGSSH 7 in conditions of light chestnut soils. Field experiments were carried out according to generally accepted methods. As a result, it was found that the growing season of new varieties of cotton corresponds to the conditions of the season in the Volgograd region. Boll opening is celebrated from 25 August to 20 September. Bushes form 4 to 18 fruits, $58 \%$ are located in the middle tier. The limiting growth and development factors include sharp drops in daytime and nighttime temperatures in spring (up to 150C). In some years, cold and rainy weather in July leads to the development of diseases on plants. However, new varieties of cotton have time to mature and form high quality fiber. Hot, dry weather does not adversely affect plant growth and development. The potential yield of these varieties reaches 3.3-3.5 t/ ha. These varieties have good prospects for implementation. The development of varietal agricultural technology will ensure the organization of cotton production in areas with long daylight hours.
\end{abstract}

\section{Introduction}

The main task of modern cotton breeding is the creation of new varieties, a way to grow in conditions of long daylight hours and having high quality fiber $[1,2]$. The emergence of breeding material with such characteristics makes it possible to expand the area of cultivation of this crop [3,5]. In the southern regions of modern Russia, there is an unsuccessful experience of growing cotton. In the 19th century, in the Astrakhan, Volgograd, Saratov regions, in the Stavropol Territory, Dagestan, they tried to grow varieties with a growing season of 150-160 days [4]. The cotton plant did not have time to ripen. Yields were low, less than $1 \mathrm{t} /$ ha [6]. The quality was only suitable for processing into the production of cotton wool.

${ }^{*}$ Corresponding author: agrosad@inbox.ru 
Thanks to purposeful work on hybridization of complex interspecific and interspecific crosses of Gossypium hirsutum L. and G. barbadense L., breeding material of a new generation was obtained, which is distinguished by early maturity and high quality fiber [7]. Russian scientists of the Volgograd State Agrarian University with breeders of the research institute of selection, seed production and agricultural technologies of cotton in the Republic of Uzbekistan. However, further breeding work should be based on the agrobiological assessment of varieties and lines in light chestnut soils.

Volgograd region at 48 parallel north latitude. It occupies a borderline position between areas with long and short daylight hours. The growth and development of cotton is greatly influenced by the light regime during the cultivation period. This plant belongs to the short day group. To promote culture to relatively northern regions, it is necessary to create varieties with high ecological plasticity [8]. A comprehensive agrobiological assessment in the area of introduction makes it possible to identify promising breeding material $[9,10]$.

The aim was to study a complex of physiological indicators, varieties and lines of cotton, research of promising donors of economic securities.

Due to a significant reduction in the supply of raw cotton from Central Asia to the Russian Federation, it is necessary to increase the volume of production of this raw material in areas suitable for growing cotton, including in the Volgograd region. According to the Ministry of agriculture, the maximum area of cotton cultivation can reach more than 200 thousand hectares, including about 10 thousand hectares in the Volgograd region.

\section{Objects and technique}

The research was carried out on a collection of varieties and lines of cotton Gossypium hirsutum L. and G. barbadense L. of various geographical origin. Field experiments were carried out at the experimental site of the Volgograd State Agrarian University in 20142020. During the growing season, the necessary phenological observations, studies of growth, water regime, and yield records were carried out. The morphobiological description of all the initial forms and hybrids involved in the experiment was carried out at the end of August, with a preliminary calculation of the labeled plants according to the variants. At the same time, the height of the plant, the height of the first sympodia and monopodia on the plant was determined, the date of the opening of the first capsule in $50 \%$ of the plants was noted. Laboratory analyzes were carried out on the test samples, where they determined: the mass of raw cotton of one boll, the mass of 1000 seeds, fiber yield, fiber length and fiber index. Fiber quality indicators were measured on an HVI analyzer in the laboratory of the Kamyshin textile mill. The data obtained were subjected to statistical processing.

\section{Results and discussion}

Currently, the vector of cotton breeding is primarily aimed at increasing crop yields and the quality of its fiber. At the same time, plant resistance to a complex of pests and diseases is also important. The need for development in this direction is also due to the fact that many countries of the world are forming their own genomic centers. It can be stated that today the world has formed a complex of knowledge in the field of genomics, proteomics, bioinformatics and biotechnology of cotton. Based on world data, it is advisable to plan research aimed at creating unique Russian varieties and hybrids of cotton.

The introduction of cotton in the crop rotation in the South of Russia will significantly improve the ecological situation, since due to the oversaturation of sown areas with grain, sunflower, vegetable crops, and in recent years, severe epiphytotics have developed, significantly reducing the yield of traditional crops. The experience of other countries 
shows that cotton is well combined in crop rotations with wheat and other cereals, corn, potatoes, and vegetables.

There are a number of factors that are limiting for cotton cultivation in the conditions of the Volgograd region. the Main ones are specific meteorological conditions of crop cultivation and low resistance of Volgograd cotton varieties and hybrids to phytopathogens. One of the urgent problems of breeding work with zoned cotton varieties is to improve the quality of raw materials obtained.

In the modern world, despite the rapid development of cotton growing, the task of creating high-yielding, high-quality, precocious and resistant to various biotic and abiotic environmental stresses of cotton varieties remains urgent. Insufficient implementation of modern scientific developments in these areas hinders the innovative development of the cotton complex.

Analysis of the photoperiodic reaction of cotton hybrids made it possible to reveal the peculiarities of development under conditions of a long day. This is the suspension of growth after the emergence of shoots, reduced bud formation and flowering by $12 \%$ (table 1).

Table 1. - Features of seasonal development of the precocious grade of PGSSH 1 cotton in the conditions of a long day.

\begin{tabular}{|c|c|c|c|c|c|}
\hline $\begin{array}{c}\text { Development } \\
\text { phase }\end{array}$ & Seedlings & Budding & $\begin{array}{c}\text { The } \\
\text { beginning of } \\
\text { flowering }\end{array}$ & $\begin{array}{c}\text { Flowering - } \\
\text { fruiting }\end{array}$ & Maturation \\
\hline $\begin{array}{c}\text { Terms of } \\
\text { passage }\end{array}$ & May 15-27 & June $16-23$ & $\begin{array}{c}\text { June } 24-\text { July } \\
07\end{array}$ & July $08-30$ & $\begin{array}{c}01-20 \\
\text { September }\end{array}$ \\
\hline Day length & $14 \mathrm{~h} 30 \mathrm{~min}-$ & $\begin{array}{c}15 \text { hours } 20 \\
\text { minutes }-15 \\
\text { hours } 30 \\
\text { minutes }\end{array}$ & $\begin{array}{c}15 \text { hours } 30 \\
\text { minutes }\end{array}$ & $\begin{array}{c}15 \mathrm{~h} 15 \mathrm{~min}- \\
15 \mathrm{~h} 20 \mathrm{~min}\end{array}$ & $\begin{array}{c}12 \text { hours } 12 \\
\text { minutes } 13 \\
\text { hours } 10 \\
\text { minutes }\end{array}$ \\
\hline $\begin{array}{c}\text { Deviation } \\
\text { from the } \\
\text { norm }\end{array}$ & $30-40$ minutes & $40-50$ minutes & 55 minutes & $45-50$ minutes & $10-15$ minutes \\
\hline $\begin{array}{c}\text { Plant } \\
\text { reaction }\end{array}$ & stunted grows & $\begin{array}{c}\text { less buds are } \\
\text { laid by } 12 \%\end{array}$ & $\begin{array}{c}\text { less flowers } \\
\text { are formed by } \\
12 \%\end{array}$ & $\begin{array}{c}\text { long ripening } \\
\text { of fruits } \\
\text { (capsules) }\end{array}$ & not \\
\hline
\end{tabular}

The data obtained when processed by the method of analysis of variance proved the differences between the varieties. The shortest growing season was observed in C-9070 and PGSSH - 1, which ripened within 110-115 days; in other varieties, the length of the growing season reached 120-130 days. Some hybrids showed a lower value of the trait, such as L - 396 b2 x S-6530, S-6530 x S-6532, PGSSH - 1 x S-6770, maturing in 104-112 days. The hybrid combinations L - 396 b2 x C-6532 and C-6530 x PGSSH - 1, where the average values of the studied trait were 7-9 days higher, turned out to be the most lateripening. Of the 15 straight hybrids studied, positive heterosis was manifested in 4 cases, in 3 cases with intermediate inheritance, the best parent dominated, in two cases - the worst parent. Negative heterosis was shown by 4 hybrids, which turned out to be promising from a breeding point of view.

At the same time, the growing season of the culture fits well into the phenological seasons of the year. The amount of heat in the Volgograd region is sufficient for the normal development of cotton. With early spring sowing (at the end of April), the opening of the first bolls occurs already at the end of August. Significant differences in the timing of the passage of the main phenological phases between short-day and long-day forms are observed during the period of budding and flowering. 
The study of the growth of early ripening and mid-ripening hybrids showed that at the beginning of the growing season, cotton grows slowly. When the air temperature drops below 15 degrees, with sharp fluctuations in daily temperatures, growth stops. With the onset of a favorable period in the middle of summer, it quickly grows in height and branches. By the time of harvesting, the height of the plants is $0.7-1.2 \mathrm{~m}$ (table 2).

Table 2. - Dynamics of cotton height growth of different maturation periods.

\begin{tabular}{|c|c|c|c|c|}
\hline \multirow{2}{*}{$\begin{array}{c}\text { Seasonal } \\
\text { development } \\
\text { phase }\end{array}$} & \multicolumn{2}{|c|}{ Ripe varieties } & \multicolumn{2}{c|}{ Medium-ripe varieties } \\
\cline { 2 - 5 } & timing & plant height, m & timing & plant height, $\mathrm{m}$ \\
\hline Seedlings & May 5-10 & $0.04-0.05$ & May 7-12 & $0.04-0.05$ \\
\hline 2 true leaves & May 25-27 & $0.10-0.12$ & June 1-3 & $0.10-0.12$ \\
\hline 4 true leaves & June 1-5 & $0.12-0.16$ & June 10-15 & $0.12-0.15$ \\
\hline 6 true leaves & June 10-15 & $0.17-0.18$ & June 20-22 & $0.16-0.17$ \\
\hline Budding & June 18-23 & $0.23-0.27$ & July 1-5 & $0.29-0.32$ \\
\hline $\begin{array}{c}\text { Flowering } \\
\text { Flom July 25 }\end{array}$ & $0.30-0.35$ & From 18 July & $0.38-0.42$ \\
\hline $\begin{array}{c}\text { Opening the } \\
\text { first fruit }\end{array}$ & $23-27$ August & $0.80-1.00$ & September 18-20 & $1.10-1.20$ \\
\hline $\begin{array}{c}\text { Mass } \\
\text { fruiting }\end{array}$ & September 5-10 & $0.80-1.00$ & From October 1 & $1.10-1.20$ \\
\hline
\end{tabular}

A comprehensive assessment of the natural resource potential of the region showed that out of the five analyzed criteria for growing cotton, the greatest compliance is observed for the length of the growing season and the sum of effective temperatures. Abiotic factors limiting the growth of cotton were identified. These include sudden temperature fluctuations during the growing season. So in the summer months, the amplitude during the day can reach 12-15 degrees. The length of daylight hours in June and July is 40-50 minutes longer. Early ripening selection samples, as a result of intensive flowering and fruiting from July, suspend the growth of bushes in height, compared with mid-season forms. Despite the fact that growth is limited by chasing, the rate of increase in the linear dimensions of plants is different and this process is influenced by the intensity of fruiting.

The 6 varieties involved in the experiment significantly differ among themselves in the productivity of raw cotton of one plant and are divided into 3 groups. The highest indicator of the productivity of raw cotton of one plant was in the C-6530 variety $-176.5 \mathrm{~g}$.

The second group includes varieties L-396 B2, S-9070, PGSSH 1, where this average indicator was at the level of 145.1-154.5 g. Varieties C-6770 and C-6532 have the average productivity of raw cotton per plant was at the level of 128.7-130.5 g. Of the 15 direct hybrid combinations studied, positive heterosis was detected in 6 cases in L-396 B2 x C6532, C-6530 x C-6770, C-6530 x C-6532, PGSSH - 1 x S-6770, PGSSH - 1 x S-6532, S$6770 \times$ S-6532. In 4 cases the best parent dominated, one hybrid combination showed negative heterosis, in 4 cases the worst parent dominated. The highest values of the 
productivity of raw cotton of one plant (176.6-177.4 g) were in the hybrids C-6530 x C6532 and C-6530 x C-6770.

Predicting the success of growing a cotton variety or hybrid in a new region is one of the central problems of its introduction. However, widely used assessment methods take into account only individual indicators at the intraspecific level, mainly associated with the action of limiting factors.

The hypothesis of the success of the cultivation of cotton plants under new conditions, taking into account the agroclimatic indicators of the growing area in other regions and the experience of experimental introduction, is tested by constructing a dendrogram. Cluster analysis allows you to combine varieties into homogeneous groups, both by individual studied criteria, as well as comprehensively by classes (Fig. 1).

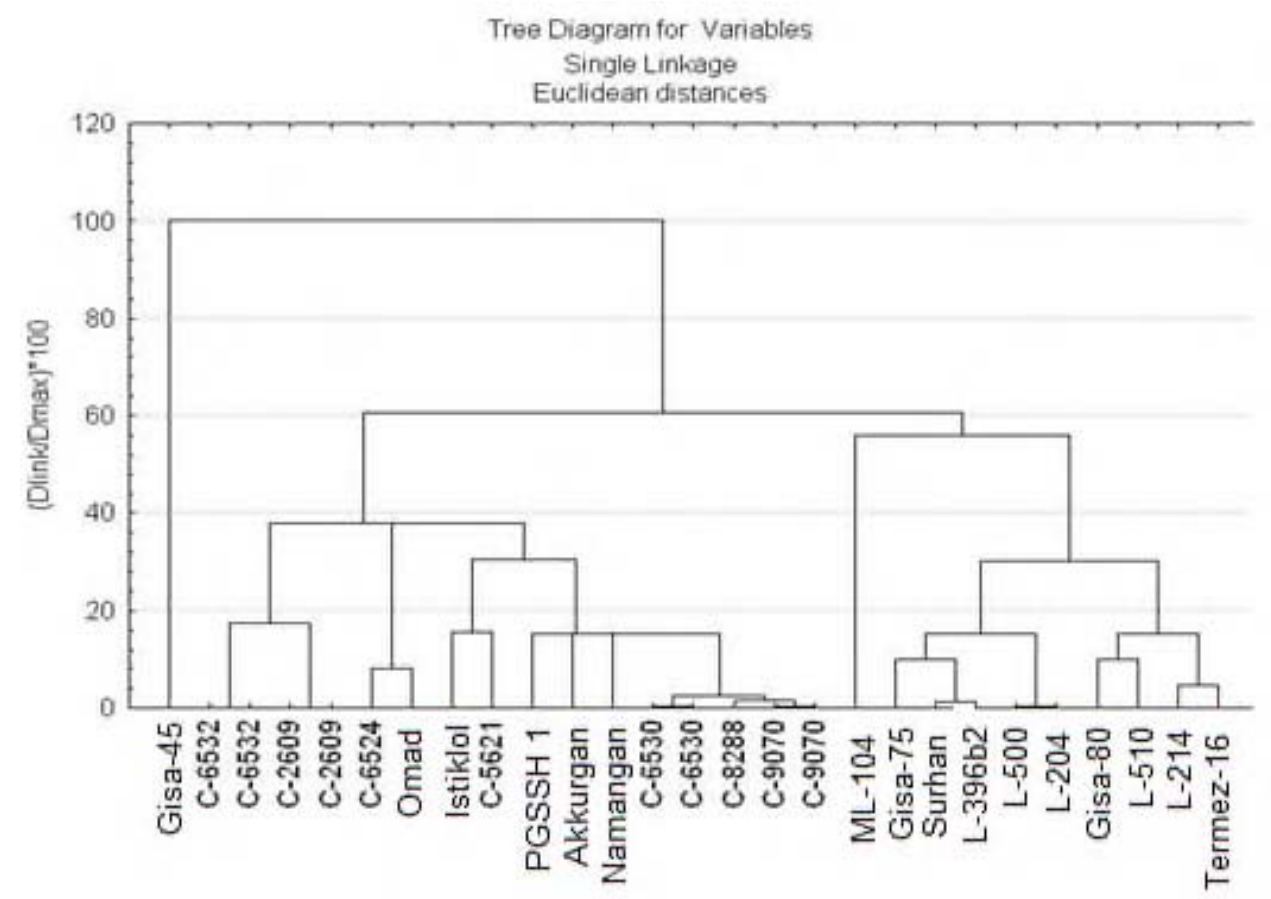

Fig. 1. Cluster grouping of the adaptive capacity of selection samples of cotton in the conditions of light chestnut soils of the Volgograd region.

The mathematical analysis of these measurements made it possible to divide the varieties into three groups. The most promising is the middle group, which includes Istiklol, S-5621, PGSSH 1, Akkurgan 2, Namangan 77, S-6530 and others. The varieties from this group are promising for hybridization and the creation of a new breeding material for the conditions of light chestnut soils.

The use of clustering in assessing the adaptive potential of cotton plants and identifying promising breeding samples can be the basis for assessing genetic donors of economically valuable traits and choosing the initial forms for hybridization. When creating new varieties for cultivation conditions in regions for a long day, special attention should be paid to early maturing forms with high fiber quality. Studies of plants in the collection showed that of all the samples involved, $73 \%$ turned out to be quite promising, $17 \%$ - promising, and $10 \%$ not promising due to low adaptive ability. 


\section{Conclusions}

Cotton is a strategically important agricultural crop: its raw materials form the basis of various industries and are of great national economic importance. In the development and intensification of domestic cotton growing, a huge role belongs to selection, obtaining ultraearly ripening varieties, characterized by high productivity, disease resistance, with high quality and quantity of fiber. The study of the adaptive abilities of varieties and lines in the collection made it possible to identify genetic donors of economically valuable traits. Selection samples Istiklol, S-5621, PGSSH 1, Akkurgan 2, Namangan 77, S-6530 and others are promising for hybridization. They have early maturity, high yield and type IV fiber. Their use in the breeding process will create a new generation of varieties for northern latitudes of cultivation.

The research was carried out with the financial support Of the administration of the Volgograd region.

\section{References}

1. V.Sadras, J. Alston, P. Aphalo, F.J. Villalobos, D. Wood. Making science more effective for agriculture. Advances in Agronomy, 163, 153-177 (2020 )https://doi.org/10.1016/bs.agron.2020.05.003/.

2. K. Singh, A.S. Bra, H.P. Singh. Drip fertigation improves water and nitrogen use efficiency of bt cotton, Journal of Soil and Water Conservation, 73. № 5, 549-557. (2018)

3. Z. Tan, Z. Zhang, X. Sun, Q. Li, Y. Sun, P.Yang, W.Wang, X.Liu, C.Chen, D. Liu, Z.Teng, K.Guo, J.Zhang. Genetic map construction and fiber quality qtl mapping using the cotton SNP80K array in upland cotton. Frontiers in Plant Science. 9. 225. (2018)

4. J. Obertreis. Irrigation and cotton cultivation in soviet central Asia: the eastern "Ecological turn", 1970S-1980S. Etudes Rurales. 200. 2. 106-129. (2017)

5. 5.L.Wang, H.Xing, Y.Yuan, X.Wang, J.Tao, W.Feng, X.Song, X.Sun, M. Saeed, G.Zhang. Genome-wide analysis of codon usage bias in four sequenced cotton species. PLoS ONE. 13. № 3. P. e0194372. (2018)

6. Z.Chen, X.Tao, H. Luo, A.Khan, D.K.Y.Tan. Biomass accumulation, photosynthetic traits and root development of cotton as affected by irrigation and nitrogenfertilization. Frontiers in Plant Science, 9. P. 173. (2018)

7. D.D.Fang, H.J.Kim. Breeding and genetics: history of cotton fiber bioscience research at USDA-ARS southern regional research center. Journal of Cotton Science, 22. № 1. 12-23. (2018)

8. W. Hu, J.L. Snider, D.R.Chastain, W.Slaton, V.Tishchenko. Sub-optimal emergence temperature alters thermotolerance of thylakoid component processes in cotton seedlings. Environmental and Experimental Botany, 155, 360-367. (2018)

9. W. Chen, M. Jin, J. Wang, J.Huang, X.Wang, Z.Wang, T.P.A.Ferré. Effect of sodium chloride and manganese in irrigation water on cotton growth, Agronomy Journal, 110. 3, 900-909. (2018)

10. O. Erdogan, H. Ozgonen-Ozkaya, M.E.Gore. The relationship of verticillium wilt and seed surface microflora with gossypol level in cotton (Gossypium Spp.). Fresenius Environmental Bulletin, 25, 12, 7695-7702. (2017) 